\begin{tabular}{cccc}
\multicolumn{4}{c}{ TABLE XIII (continued). } \\
Temperature. & Salt. & Conc. salt. & $\begin{array}{c}\text { Solubility of } \\
\text { CaSO }\end{array}$ \\
25 & $\mathrm{NH}_{4} \mathrm{Cl}^{2}$ & 201.86 & 57.28 \\
& & $456 . \mathrm{I}$ & 79.02 \\
& 873.0 & 103.85 \\
& $\mathrm{NH}_{4} \mathrm{NO}_{3}{ }^{1}$ & 124.9 & $46.7 \mathrm{I}$ \\
& 312.3 & 57.73 \\
& 687.05 & 85.19
\end{tabular}

It has been shown that the curves representing the change of solubility of a unibivalent salt, such as silver sulfate, are not at all of the form to be expected from the solubility-product principle, if the salt added contains the common bivalent ion. However, as the solubility of the dissolved unibivalent salt decreases, the curves of this type rapidly approach what might be considered to be the theoretical curve, although, even in the case of the least soluble salt yet investigated, barium bromate, the actual curve is very far from what would be expected theoretically. The results obtained in this investigation indicate that much less soluble salts would give curves very much nearer the theoretical one; and in order to test this conclusion, the solubilities of the less soluble salts, barium iodate and lead iodate, will be determined. The results are given in the sixth paper of this series. A seventh paper will contain calculations, from the data in this paper, of the ion-concentration product and the un-ionized part of the dissolved salts by the methods outlined in Paper I of this series. It will also contain a discussion of the remarkable abnormalities found in the solubility relations of unibivalent salts.

Boston, Mass.

[CONTRIBUTIONS FROM THE RESEARCh LABORATORY OF PHySical CHEMistry OF THE MassachusetTS INSTITUTE OF TeChNOLOgy, No. 77.]

\title{
THE EFFECT OF SALTS UPON THE SOLUBILITY OF OTHER SALTS. VI. THE SOLUBILITY OF DIFFICULTLY SOLUBLE UNIBIVALENT SALTS.
}

By William D. Harkins and W. J. WINNINGhoff.

Received August 28, 1911.

\section{The Solubility of Barium Iodate in Water and in Solutions of Barium Nitrate, Potassium Nitrate and Potassium Iodate.}

The results presented in the fifth paper of this series show that, for salts of moderate or of great solubility, there is a very great deviation from the solubility-product principle, when a salt with a common bivalent ion is added to the aqueous solution of a salt in contact with the solid phase and in equilibrium with it. It was observed that the form of the curve representing the change of solubility with the concentration of the added

${ }^{1}$ Cameron and Brown, J. Physic. Chem., 9, $211-13$ (1905). 
salt became more nearly what would be expected from this principle as the solubility of the "saturating salt" decreased. It is therefore of interest to determin such solubility curves for salts which are very difficultly soluble.

The salts best suited for such an investigation seemed to be the iodates of barium and lead, whose solubilities in pure water at $25^{\circ}$ are 0.001578 and $0.0001 \mathrm{IOI}$ equivalents per liter, respectively. The molal solubility of lead iodate is only three and one-half times the solubility of silver chloride, and it seems to be the most difficultly soluble unibivalent salt of such a character as to permit of analytical determinations of its concentration of sufficient accuracy. The solubility of this salt was determined in solutions of lead nitrate, potassium nitrate, and in very dilute solutions of potassium iodate. The solubility of barium iodate was determined in solutions of barium nitrate, potassium nitrate, and potassium iodate.

This investigation was carried out with the aid of a grant made to Professor A. A. Noyes by the Carnegie Institution of Washington.

The barium and lead iodates used for the solubility determinations were made by precipitating the respective nitrates with potassium iodate, in a very dilute solution in which the nitrate was kept constantly in excess. The salt was washed with conductivity water until its solubility became constant.

The barium nitrate and potassium nitrate were purified by recrystallization in the same way as was described in the fifth paper of this series. The potassium iodate was recrystallized twice from conductivity water, and the strength of the solutions was determined by analysis.

TABle I.-The Solubility OF Barium IOdATE IN WATER AT $25^{\circ}$. (Concentrations in equivalents per liter.)

\begin{tabular}{|c|c|c|c|c|c|}
\hline No. & Solubility. & Mean solubility. & $\begin{array}{l}\text { Specific } \\
\text { conductance. }\end{array}$ & $\begin{array}{l}\text { Equivalent } \\
\text { conductance. }\end{array}$ & $\begin{array}{l}\text { Gram per } \\
\text { liter. }\end{array}$ \\
\hline $\mathbf{I}$ & 0.001579 & & 0.00016820 & 106.5 & \\
\hline 2 & 0.001578 & & 0.00016834 & & \\
\hline 3 & 0.001581 & & & & \\
\hline 4 & $0.0015^{81}(s)$ & & & & \\
\hline 5 & $0.00158 \mathrm{I}(\mathrm{s})$ & & & & \\
\hline 6 & $0.001577(s)$ & & & & \\
\hline 7 & $0.001575(s)$ & 0.001579 & & & 0.3845 \\
\hline
\end{tabular}

The concentration of the "saturating salt" was determined by adding potassium iodide to the solution of the iodate, and liberating iodine by adding hydrochloric acid. The iodine was determined by titration with a 0.01 or a 0.005 normal solution of sodium thiosulfate. These dilute thiosulfate solutions were made up as needed by diluting a standard tenth-normal solution. This latter was standardized against iodine, and against a solution of pure copper sulfate. The dilute solutions were constantly checked by titrating against a o.or normal potassium iodate 
solution, which was made by weighing out the pure salt which had been dried at $120^{\circ}$. The concentration of this potassium iodate solution was checked by titrating with one of the standard thiosulfate solutions. The thiosulfate solutions were made up with water of a conductivity of about $0.80 \times 10^{-8}$, and were kept in a black bottle, which was fitted with soda lime tubes to protect the solution from the action of carbon dioxide. Even the most dilute solutions kept perfectly for a week or more when

Table II.-The Solublitity of Barium Iodate in Solutions of Barium Nitrate, Potassium Nitrate and Potassium Iodate at $25^{\circ}$.

\begin{tabular}{|c|c|c|c|c|c|c|}
\hline Ne. & $\begin{array}{l}\text { Added } \\
\text { salt. }\end{array}$ & $\begin{array}{l}\text { Conc. added } \\
\text { salt. }\end{array}$ & $\begin{array}{l}\text { Solubility } \\
\mathrm{Ba}\left(\mathrm{IO}_{3}\right)_{2} \cdot\end{array}$ & Mean sol. & $\begin{array}{l}\text { Fractional } \\
\text { conc. added salt. }\end{array}$ & $\begin{array}{l}\text { Fractiona } \\
\text { solubility }\end{array}$ \\
\hline 8 & $\mathrm{Ba}\left(\mathrm{NO}_{3}\right)_{2}$ & $0 . \infty 0 \mathrm{I}$ & 0.001361 & & & \\
\hline 9 & & & $0.001364(s)$ & & & \\
\hline I0 & & & 0.001363 & & & \\
\hline I I & & & $0.001360(s)$ & 0.001362 & 0.634 & 0.862 \\
\hline 12 & & 0.002 & $0.0012 \mathrm{I} 4$ & & & \\
\hline I 3 & & & $0.0012 \mathrm{I} 3(s)$ & & & \\
\hline I4 & & & 0.001211 & & & \\
\hline 15 & & & $0.0012 \mathrm{II}(\mathrm{s})$ & 0.001212 & I. 268 & 0.768 \\
\hline 16 & & 0.005 & 0.0009740 & & & \\
\hline 17 & & & $0.0009757(s)$ & & & \\
\hline I 8 & & & 0.0009747 & & & \\
\hline 19 & & & $0.0009770(s)$ & 0.0009753 & 3.170 & 0.619 \\
\hline 20 & & 0.020 & 0.0006739 & & & \\
\hline $2 \mathrm{I}$ & & & $0.000675^{2}$ & & & \\
\hline 22 & & & $0.0006749(s)$ & & & \\
\hline 23 & & & $0.0006737(s)$ & 0.0006744 & 12.68 & 0.427 \\
\hline 24 & & 0.050 & 0.0006128 & & & \\
\hline 25 & & & 0.0006133 & & & \\
\hline 26 & & & 0.0006 I $37(s)$ & & & \\
\hline 27 & & & 0.0006 I $27(\mathrm{~s})$ & $0.000613 I$ & $3 \mathrm{I} \cdot 7 \mathrm{O}$ & 0.388 \\
\hline 28 & & 0.100 & 0.0005663 & & & \\
\hline 29 & & & $0.0005655(s)$ & 0.0005659 & 63.4 & $0.35^{8}$ \\
\hline 30 & & 0.200 & 0.0005573 & & & \\
\hline $3 I$ & & & $0.0005587(s)$ & 0.0005580 & 126.8 & 0.353 \\
\hline 32 & $\mathrm{KNO}_{3}$ & 0.002 & 0.001624 & & & \\
\hline 33 & & & $0.001625(s)$ & 0.001624 & I. 268 & I. .029 \\
\hline 34 & & 0.010 & 0.001826 & & & \\
\hline 35 & & & $0.001827(s)$ & 0.00182 & 6.34 & I. I 55 \\
\hline 36 & & 0.050 & 0.002640 & & & \\
\hline 37 & & & $0.00264 I(s)$ & 0.002640 & 31.70 & I. $67 \mathrm{I}$ \\
\hline 38 & & 0.200 & 0.003192 & & & \\
\hline 39 & & & 0.003 I $89(s)$ & 0.003190 & I 26.8 & $2.02 I$ \\
\hline 40 & KIO & 0.00010608 & 0.001509 & & & \\
\hline $4 \mathrm{I}$ & & & $0.001512(s)$ & 0.001510 & 0.0673 & 0.908 \\
\hline 42 & & 0.0005304 & 0.001240 & & & \\
\hline 43 & & & $0.001244(s)$ & 0.001242 & 0.336 & 0.748 \\
\hline \multirow[t]{2}{*}{44} & & 0.0010608 & 0.0009416 & & & \\
\hline & & & $0.000942 \mathrm{I}$ & 0.0009418 & 0.673 & 0.596 \\
\hline
\end{tabular}

$(s)$ after a number denotes that the value was obtained by approaching equilibrium from the side of supersaturation. 
treated in this way. A weight buret was used for all of the titrations. Iodates have a special advantage when it is necessary to make analytical determinations in extremely dilute solutions, since each mol. of barium or lead iodate releases twelve equivalents of iodine from potassium iodide in acid solution.

The results of the solubility determinations, together with the densities of the solutions, are given in Tables I-IV.

\section{The Solubility of Lead Iodate in Water and in Solution of Lead Nitrate, Potassium Nitrate and Potassium Iodate.}

TABLE III.-SolubILITy OF* LEAD IOdATE IN WATER at $25^{\circ}$. (Concentrations in equivalents per liter.)

$\begin{array}{cc}\text { No. } & \text { Solubility of lead iod } \\ 46 & 0.0001105 \\ 47 & 0.0001102 \\ 48 & 0.0001107 \\ 49 & 0.0001101(s) \\ 50 & 0.0001097(s) \\ 51 & 0.0001194(s) \\ 52 & 0.0001097(s)\end{array}$

Mean.

Gram per liter.

Table IV.-Solublity of Lead Iodate in Solutions of Lead Nitrate, Potassium NITRATE AND POTASSIUM IODATE.

\begin{tabular}{|c|c|c|c|c|c|c|}
\hline No. & $\begin{array}{c}\text { Salt } \\
\text { added }\end{array}$ & $\begin{array}{l}\text { Conc. added } \\
\text { salt. }\end{array}$ & $\begin{array}{l}\text { Solubility } \\
\mathrm{Pb}\left(\mathrm{IO}_{3}\right)_{2} .\end{array}$ & $\begin{array}{c}\text { Mean } \\
\text { solubility. }\end{array}$ & $\begin{array}{l}\text { Fractional } \\
\text { conc. salt. }\end{array}$ & $\begin{array}{l}\text { Fractiona } \\
\text { solubility }\end{array}$ \\
\hline 53 & $\mathrm{~Pb}\left(\mathrm{NO}_{3}\right)_{2}$ & $0.000 \mathrm{I}$ & 0.0000870 & & & \\
\hline 54 & & & $0.0000870(s)$ & 0.0000870 & 0.908 & 0.790 \\
\hline 55 & & 0.001 & 0.0000408 & & 9.08 & 0.373 \\
\hline $5^{6}$ & & & $0.0000414(s)$ & $0.00004 \mathrm{Ir}$ & $\ldots \ldots$ & $\ldots$ \\
\hline 57 & & 0.010 & 0.0000185 & & & \\
\hline $5^{8}$ & & & $0.0000186(s)$ & 0.0000185 & 90.8 & 0.169 \\
\hline 59 & & 0.100 & 0.000016 & & & \\
\hline 60 & & & $0.000016(s)$ & 0.000016 & 908.0 & 0.145 \\
\hline $6 \mathrm{I}$ & & 0.500 & $(0.000030)$ & & & \\
\hline 62 & & & $(0.000027)(s)$ & $(0.000028)$ & 4590.0 & $(0.259)$ \\
\hline 63 & & 3.0 & $(0.00015)$ & & & \\
\hline 64 & & & $(0.00015)(s)$ & $(0.00015)$ & 27240.0 & $\ldots$ \\
\hline 65 & $\mathrm{KNO}_{3}$ & 0.002 & 0.0001145 & & & \\
\hline 66 & & & $0.0001138(s)$ & 0.0001141 & I 8.16 & I. 039 \\
\hline 67 & & 0.010 & 0.0001334 & & & \\
\hline 68 & & & $0.0001334(s)$ & 0.0001334 & 90.8 & 1.211 \\
\hline 69 & & 0.050 & 0.0002037 & & & \\
\hline 70 & & & $0.0002037(s)$ & 0.0002037 & 454.0 & I. 848 \\
\hline 71 & & 0.200 & 0.0002548 & & & \\
\hline 72 & & & $0.0002540(s)$ & 0.0002544 & 1816.0 & 2.311 \\
\hline 73 & $\mathrm{KIO}_{3}$ & 0.00005304 & 0.0000717 & & & \\
\hline 74 & & & 0.0000697 & 0.0000697 & & \\
\hline 75 & & & 0.00007 I $4(s)$ & & & \\
\hline 76 & & & $0.0000734(s)$ & 0.00007 I 5 & 0.482 & 0.65 \\
\hline 77 & & 0.0001061 & 0.0000432 & & & \\
\hline & & & $0.0000442(s)$ & 0.0000437 & 0.963 & 0.493 \\
\hline
\end{tabular}




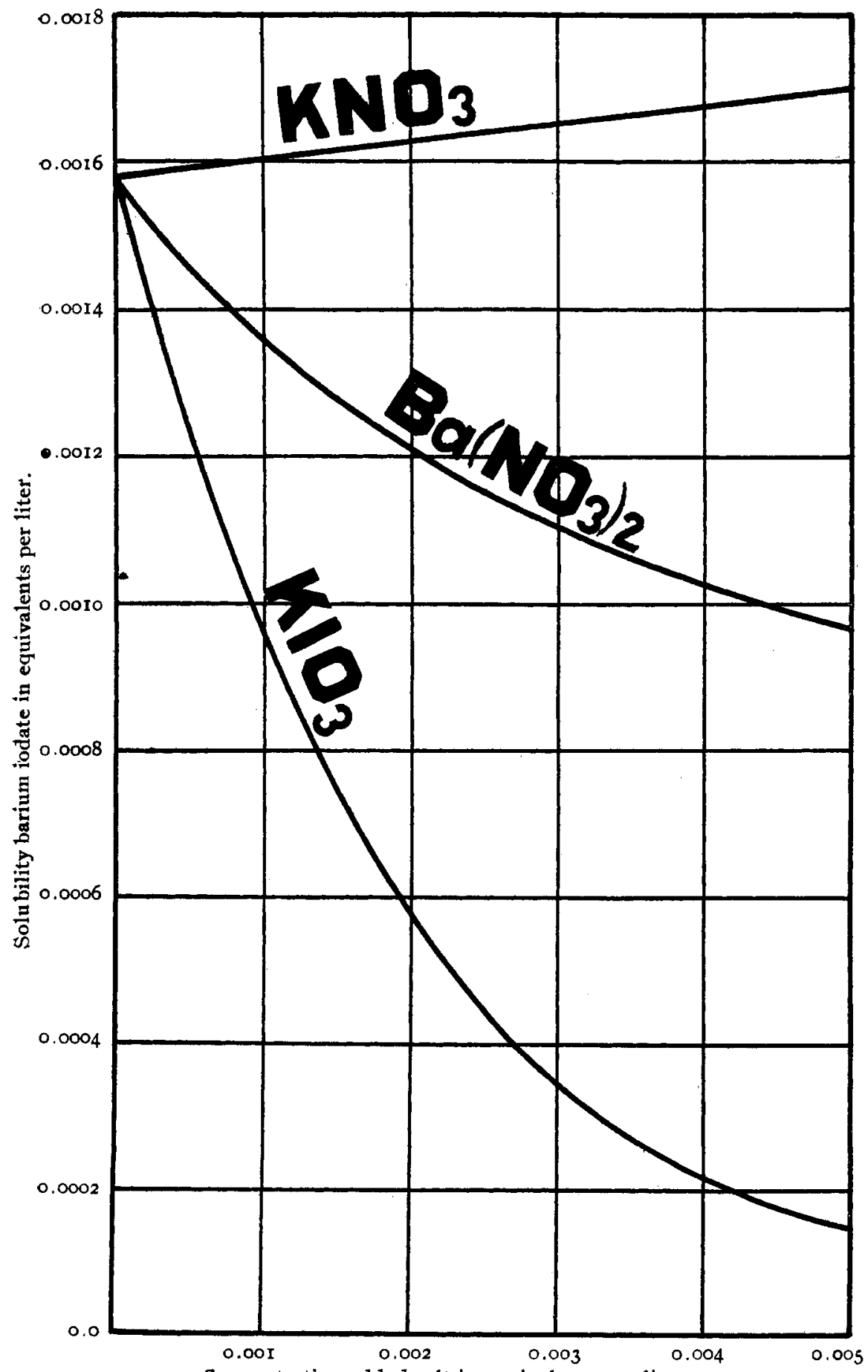

Concentration added salt in equivalents per liter.

Fig. I. 
The results of these tables, with other results ased for purposes of comparison, are plotted in Figs. I-3, where the abscissas represent the equivalent concentration of the added salt. In Figs. I and 2 the ordinates represent the equivalent solubility, while in Fig. 3 they represent the fraction of the solubility in water, or the ratio of the solubility of dissolved salt in salt solution to its solubility in water. The curves for barium iodate presented in Fig. I have, at least qualitatively, the form which would be expected from the solubility-product principle. The curve representing the addition of a salt with a common univalent ion falls with extreme rapidity, and much more rapidly than the similar

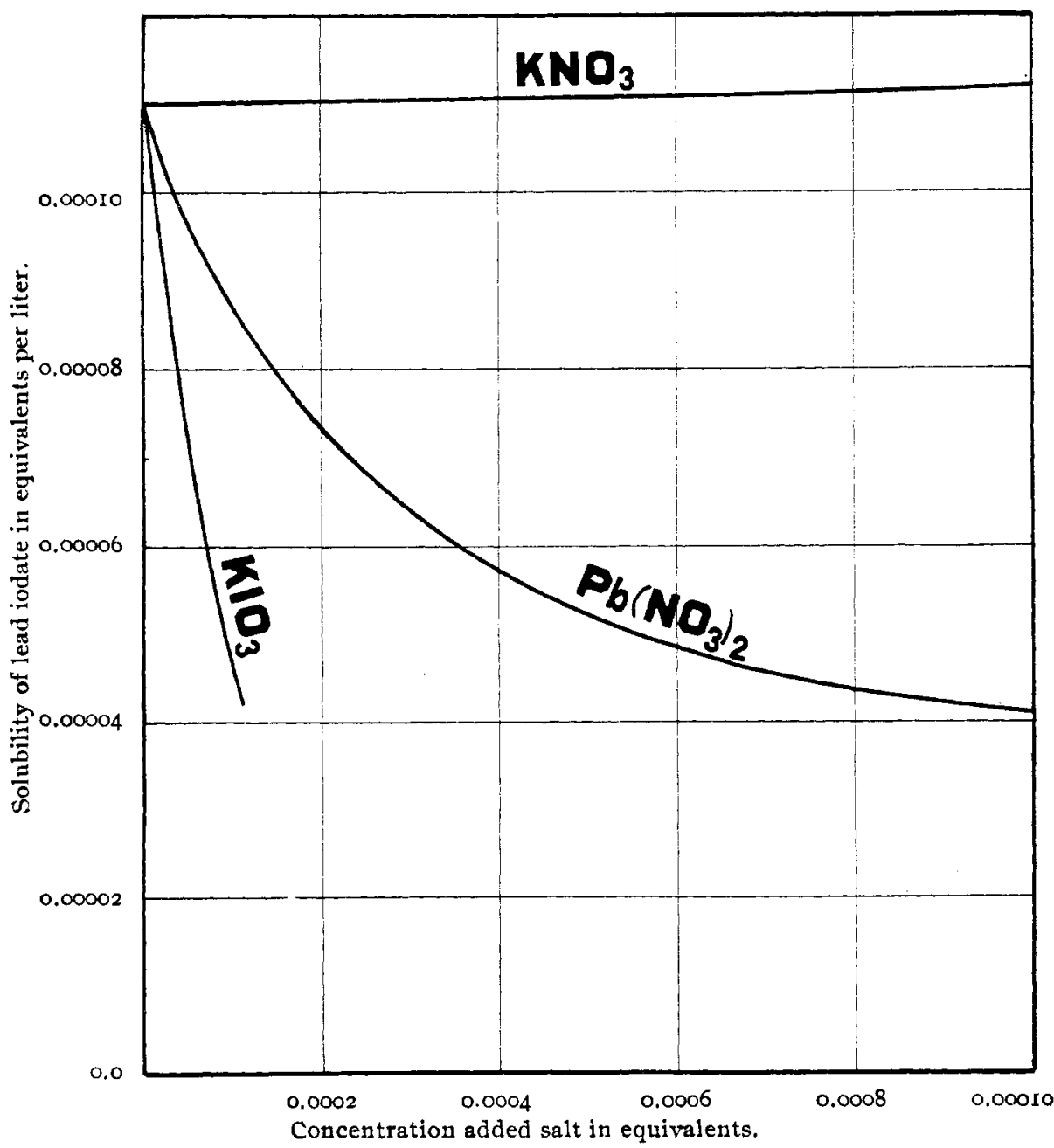

Fig. 2. 
curves for the more soluble salts considered in the fifth paper of this series. The corresponding curve for lead iodate drops very much more rapidly than that for barium iodate.

The curves representing the addition of a salt with a common bivalent ion also drop very rapidly, which is contrary to what was found for the more soluble salts.

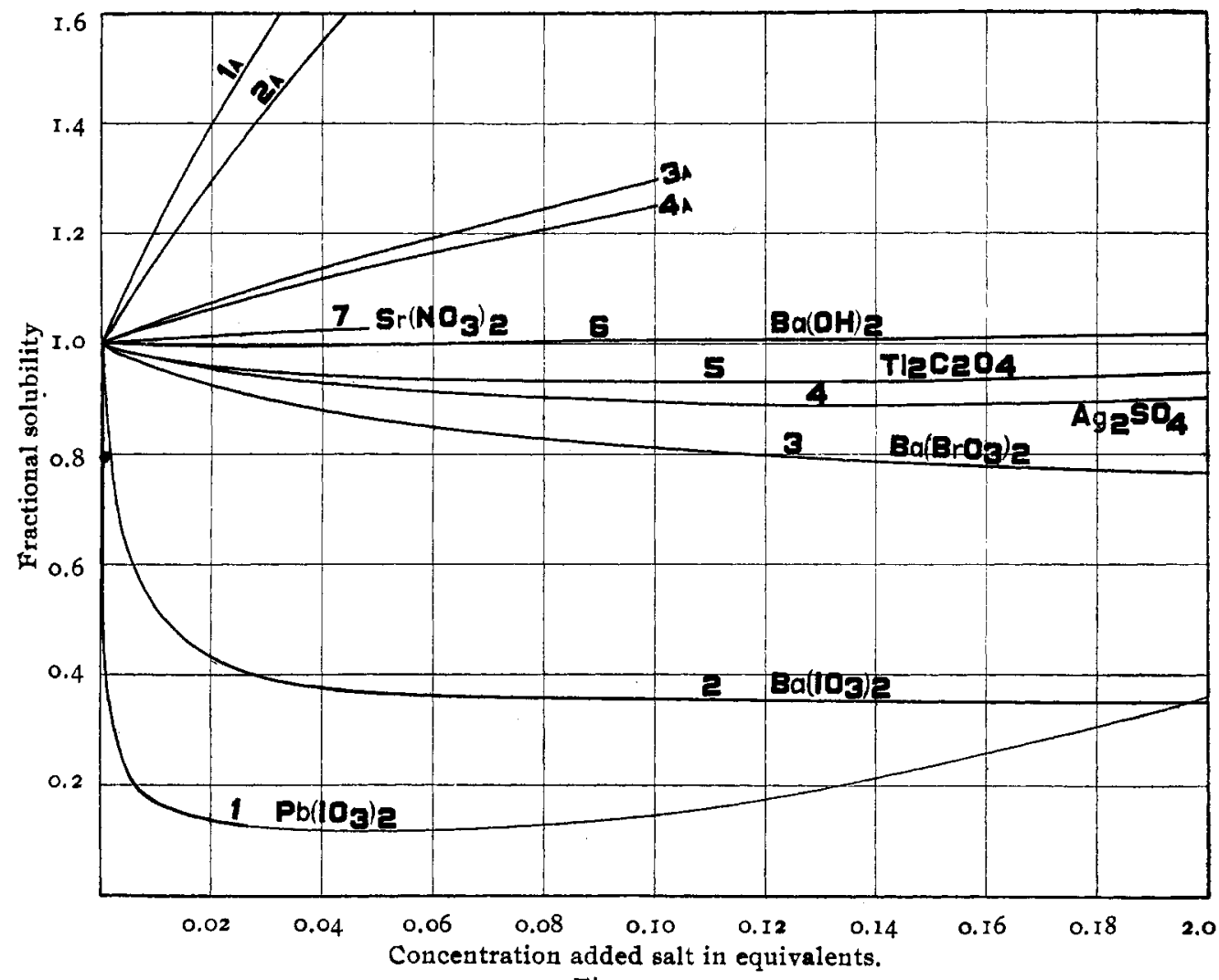

Fig. 3.

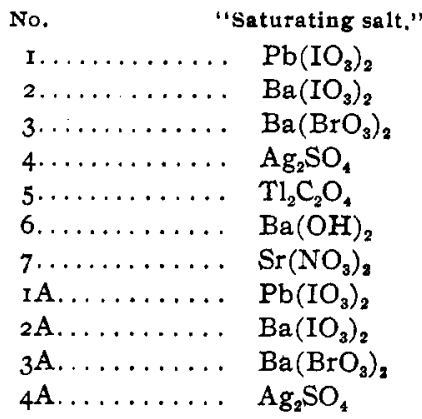

Solubility in water.

Added salt.

$\begin{array}{ll}0.0001102 & \mathrm{~Pb}\left(\mathrm{NO}_{8}\right)_{2} \\ 0.001579 & \mathrm{Ba}\left(\mathrm{NO}_{3}\right)_{2} \\ 0.04018 & \mathrm{Ba}\left(\mathrm{NO}_{3}\right)_{2} \\ 0.05352 & \mathrm{~K}_{2} \mathrm{SO}_{4} \\ 0.07536 & \mathrm{~K}_{2} \mathrm{C}_{2} \mathrm{O}_{4} \\ 0.562 & \mathrm{Ba}\left(\mathrm{NO}_{3}\right)_{2} \\ 6.176 & \mathrm{Sr}(\mathrm{OH})_{2} \\ 0.0001102 & \mathrm{KNO}_{3} \\ 0.001579 & \mathrm{KNO}_{3} \\ 0.04018 & \mathrm{KNO}_{3} \\ 0.05352 & \mathrm{KNO}_{3}\end{array}$


The curves for the addition of a salt with no common ion rize very slowly in these figures, but it must be remembered that the concentration of the added salt is given on a very much larger scale than in Fig. I of the fifth paper, since the scale is ten times as great for barium iodate, and one hundred times as great for lead iodate.

In Fig. 3 the concentration of the added salt has been plotted on nearly the same scale as that used for Fig. I of the fifth article, so that the two figures may be more easily used for purposes of comparison. However, on account of the great differences in solubility it is impossible to plot the curves for barium iodate and lead iodate in the same figure with any degree of accuracy if the equivalent solubilities are plotted on the $\mathrm{Y}$ axis, so, instead, all of the curves have been given a common origin. The curves for the addition of the common univalent ion are not represented, since, up to the highest concentrations at which the determinations were made these curves have here become practically coincident with the $\mathrm{Y}$ axis, which illustrated the extreme rapidity of the decrease in solubility. The curres presented are those for the common bivalent ion, and for no common ion.

When the curves for the common bivalent ion are considered, it is seen that the solubility of the most difficultly soluble salt, lead iodate (0.000I IOI equivalent per liter in water), falls to 0.37 of its original value when the solution contains 0.00 I equivalent of lead nitrate per liter, ${ }^{1}$ and in o.or normal lead nitrate the solubility falls to 16.9 per cent.

As an interesting minor point it should be noted that the curve representing the effect of the addition of lead nitrate to lead iodate in its saturated solutions, turns upward when the concentration of the added salt rizes much above 0.05 normal, and the increase in solubility observed is abnormal. It will be remembered that a similar abnormality was observed when lead nitrate was added to dissolved lead chloride. This abnormality would, then, seem to be characteristic of lead salts, and dependent upon the total salt or ion concentration, rather than upon the solubility of the salt itself. This curve for concentrations of the added salt greater than $0.025 \mathrm{~N}$ has been drawn as a light line in Fig. 3, since the determinations were not very accurate, on account of the very small

1 Even this decrease is very small when compared with that caused by a salt containing a common univalent ion, since in the latter case the addition of a salt with a concentration of one-ten-thousandth normal decreases the solubility to 39 per cent. of its original value. If such facts as these were better understood by analysts in general they would add a much smaller excess of the salt used for the precipitations, and thereby reduce the amount of adsorbed salt, and decrease the amount of washing necessary. In this case the addition of so small an amount of potassium iodate as to make the solution 0.00044 normal with respect to this salt, would decrease the solubility of $\mathrm{Pb}\left(\mathrm{IO}_{3}\right)_{2}$ to 0.07 of its value in water, and this decrease would be even more rapid for a less soluble salt. 
concentration of the lead iodate present in a solution containing so large an amount of lead nitrate. This latter was precipitated, by the potassium iodide used in the analysis, in the form of lead iodide. This lead iodide oxidizes readily, and the amount oxidized would be added to the concentration of the lead iodate. The determinations in the dilute solutions are not affected by this error.

Table $\mathrm{V}$ gives the percentage change in the solubility of the unibivalent salts plotted in Fig. 3, which is caused by making the solution of the salt o.or normal with respect to a salt which contains a common bivalent ion or a salt.

Table V.-Percentage Change in the Solubility of Unibivalent Salts Caused by Making the Solution o. or Normal with Respect to $A$, a Salt with a

Common Bivalent Ion, $B$, a Salt with no Common Ion (viz., POTASSIUM Nitrate).

\begin{tabular}{|c|c|c|c|}
\hline Salt. & $\begin{array}{l}\text { Equivalent solu- } \\
\text { bility in water. }\end{array}$ & $\begin{array}{l}\text { Percentage } \\
\text { decrease } \\
\text { in solubility } \\
\text { caused by } A .\end{array}$ & $\begin{array}{l}\text { Percentage } \\
\text { increase } \\
\text { in solubility } \\
\text { caused by } B .\end{array}$ \\
\hline $\mathrm{Pb}\left(\mathrm{IO}_{3}\right)_{2} \ldots \ldots \ldots \ldots \ldots$ & 0.000110 & 83.1 & $2 \mathrm{I} . \mathrm{I}$ \\
\hline $\mathrm{Ba}\left(\mathrm{BrO}_{3}\right)_{2} \ldots \ldots \ldots \ldots \ldots$ & . 0.001578 & 48.0 & I $5 \cdot 5$ \\
\hline $\mathrm{Ba}\left(\mathrm{BrO}_{3}\right)_{2} \ldots \ldots \ldots \ldots$ & 0.04018 & 4.3 & $3 \cdot 7$ \\
\hline $\mathrm{Ag}_{2} \mathrm{SO}_{4} \ldots \ldots \ldots \ldots \ldots$ & 0.05352 & $3 \cdot 3$ & $3 \cdot 3$ \\
\hline $\mathrm{Tl}_{2} \mathrm{C}_{2} \mathrm{O}_{4} \ldots \ldots \ldots \ldots \ldots$ & 0.07536 & 2.7 & . \\
\hline $\mathrm{PbCl}_{2} \ldots \ldots \ldots \ldots \ldots$ & 0.07776 & 0.09 & . \\
\hline $\mathrm{Ba}(\mathrm{OH})_{2} \ldots \ldots \ldots \ldots \ldots$ & $0.5^{62}$ & 0.01 & .. \\
\hline $\mathrm{Sr}\left(\mathrm{NO}_{3}\right)_{2} \ldots \ldots \ldots \ldots \ldots$ & 6.18 & $-0.08^{1}$ & .. \\
\hline
\end{tabular}

Fig. 3 and Table $V$ deserve careful consideration, as they contain results of great significance. It is unfortunate that no curve has been determined for the solubility of strontium nitrate in a solution of a salt with no common ion, such as potassium chloride; but it may be predicted from the results presented in the figure and the table that this curve will lie practically as low as the curve representing the solubility of strontium nitrate in solutions of strontium hydroxide. In other words, the curves representing the effect of a salt with a common bivalent ion and with no common ion have become practically coincident, at least when the concentration of the added salt is small. This would seem to lead to the interpretation that a 6-normal strontium nitrate solution and a o.or normal strontium hydroxide solution have practically no ion in common. The most easily reached explanation of the facts in this case seems to be that presented in the seventh paper of this series, where the assumption is made that very concentrated solutions of a unibivalent salt, using strontium nitrate for an example, consist most largely of the un-ionized salt and the ions $\mathrm{SrNO}_{3}{ }^{+}$and $\mathrm{NO}_{3}-$, and only an extremely small amount of the $\mathrm{Sr}^{++}$ion, while the solution of strontium hydroxide would consists in this concentrated salt solution, on the basis of the same hypothesis,

${ }^{1}$ That is, 0.08 per cent. increase. 
most largely of $\mathrm{SrOH}^{-}$and $\mathrm{OH}^{+}$ions and un-ionized $\mathrm{Sr}(\mathrm{OH})_{2}$ with only an extremely small amount of the $\mathrm{Sr}^{++}$ion. Under this assumption the ions present, resulting from the dissociation of the two salts, would be almost altogether non-common ions, and the resulting curve should therefore have the same form as for the addition of a salt with no common ion.

Boston, Mass.

[Contributions from the Research Laboratory of Physical Chemistry of the MASSACHUSETTS INSTITUTE OF TEChNOLOGY. No. 78.]

\section{THE EFFECTS OF SALTS UPON THE SOLUBILITY OF OTHER SALTS. VII. DISCUSSION OF THE SOLUBILITY RELATIONS OF UNIBIVALENT SALTS.}

BY WiLltaM D. Harkins.

Received August 28, 1911.

\section{I8. Introduction.}

The data and discussion of the fifth and sixth papers of this series show that the solubility-product principle cannot be even approximately true for moderately soluble salts of the unibivalent type, when a common bivalent ion is added, if the concentration of the un-ionized part remains constant, or varies in the same direction as it always does with uni-univalent salts. In the case of this latter, more simple type of salt the concentration of the un-ionized part of the dissolved salt always decreases with the increase in total ion concentration. ${ }^{1}$ If this is true for unibivalent salts, the increase of solubility caused in some cases by the addition of a salt with a common bivalent ion must be accompanied by an enormous increase in the solubility-product. It is therefore of interest to consider these solubility data from a quantitative standpoint, in order to see how much of the variation of the solubility curves from what has been considered the theoretical form may be due to deviations from the solubility-product principle, and how much may be due to irregular behavior on the part of the un-ionized fraction.

With this end in view, calculations of the concentrations of the ionized and un-ionized parts of all of the salts have been made by the methods which have been employed in the study of uni-univalent salts. The method of calculation has been explained in the first paper of this series and illustrated in the fourth paper. ${ }^{2}$ It may be recalled that when no common ion is present the total ion concentration $(\Sigma i)$ is taken as the factor determining the ionization relations of the salts. A fundamental assumption made in this method of calculation is that intermediate ions of the type $\mathrm{AgSO}_{4}^{-}$or $\mathrm{BaBrO}_{3}^{+}$are not present. Indeed, it/ is

${ }^{1}$ See article IV of this series, This JOURnaL, 33, I683-5 (1911).

'See also Sherrill, This JoURNAL, 32, 74 (1910). 